\title{
Human Behaviors Encountered During the Different Phases of the Kondratieff cycle
}

\author{
Theodore Modis \\ GROWTH DYNAMICS
}

2, rue Beau Site, Geneva, Switzerland

\begin{abstract}
There are different behaviors appropriate to the different phases of growth. This has been observed among species in nature as they go through the four seasons, but also among humans in society as different economic-growth phases succeed one another. Typically, difficult times stimulate entrepreneurship whereas prosperity nurtures conservatism. Less obviously, preoccupation with the "what" characterizes formative times whereas preoccupation with the "how" characterizes periods of maturity.

A multitude of different behaviors can be mapped on the four phases of any growth cycle. On a larger scale, and to the extent that society is anthropomorphic, society as a whole goes through different behaviors while experiencing transitions between cyclical phases of growth. Given a growth phase we can expect specific behaviors, and inversely, given a specific behavior we can deduce the growth phase being traversed. It follows that WWII may have been survival-driven whereas WWI greed-driven.
\end{abstract}

\section{Introduction}

Borrowing images from biology to fit the marketplace is not new. Companies and organizations resemble living organisms. They are born; mature; get married; have daughters; become aggressive, sleepy, or exhausted; grow old; and eventually die or become prey to a voracious predator. As early as the turn of the century, enlightened economists and broad-minded physicists applied scientific notions such as periodic harmonic motion and Darwin's survival of the fittest to human products. In 1918 Lotka successfully predicted the size of the American railway network, via mathematical formulations from biology [1]. At about the same time (1926), the Russian economist Nikolai D. Kondratieff was establishing evidence for a long economic wave with a period of 50 to 60 years. This claim scored high points in popularity when the stock market crashed in 1987 and continued to score high with the persisting depression-like economy that, as had happened 58 years earlier, followed the 1987 crash.

Periodic swings of the economy are echoed in the preachings of management consulting gurus, who may pass easily from thesis to antithesis, and do not stop short of giving contradicting messages. Do you see your organization indulging in business process reengineering and total quality at the same time? Have you reconciled the benefits of leadership with those of empowerment and self-managed teams? Advocates of centralized control and vertical integration became rather quiet in the 1990s. Instead we heard about business units, core competencies, and horizontal corporations. These changes do not reflect conceptual breakthroughs in the theory of doing business. They are simply reactions to the economic climate and its seasonal variation. 
Throughout history, periods of bureaucracy and control interspersed by waves of innovation and entrepreneurship. Notorious bureaucracies, such as the Roman Empire and the British civil service, were preceded and followed by entrepreneurial eras, such as crusades and revolutions (both social and industrial). The way to do business has followed suit. Many have addressed the question of how organizational behavior evolves over time. But it was Niccolo Machiavelli-early in the 16th century-who first pointed out the importance of adaptation. He wrote in The Prince: "I believe also that he will be successful who directs his actions according to the spirit of the times, and that he whose actions do not accord with the times will not be successful."

\section{The Kondratieff Wave as a Sequence of Life Cycles}

When S-curves cascade their respective life cycles give rise to a succession of bell-shaped peaks. A question often asked by marketers is the timing of the introduction of the followup curve. If the replacement product is introduced too early, it results in "cannibalization" of the previous product's sales. If the new-product introduction is too late, competition may get a foothold in the company's client base. Is there an optimum timing for the introduction of the second curve? The answer given below is based on harmony not on optimization, but to the extent that harmony generally involves paths of least resistance, optimization may also be invoked.

The natural growth processes, shown by S-curves at the top of Figure 1 cascade in a harmonic way. The word harmonic is used rigorously here. It means that the processes cascade in such a way that the overall envelope (shown in the lower graph of Figure 1) traces a sine wave, hallmark of harmonic motion [2]. That is the way a pendulum moves. The implication is that the new process must have penetrated its market niche by 1 percent when the old process approaches filling its own market niche to 90 percent. This corresponds to just-in-time product replacement. It ensures that when the old product reaches the end of its life cycle ( 99 percent of total sales) the new product has come out of "infant mortality" with 7 percent penetration of its own market niche and can thus assume the main thrust of the new growth phase. On the time axis of Figure 1 we see precisely how the market penetration levels should overlap.

Just-in-time replacement is based on the intellectually appealing hypothesis that harmony should be associated with sustained natural growth. There is hard evidence that corroborates this hypothesis, however. Market-niche succession-documented by datahas followed this rule on at least two occasions: in energy consumption worldwide, and in the evolution of coal production in the United States over the last 150 years, reported in Predictions [3]. Both cases depict a pattern identical to that of Figure 1.

The overall drop associated with the period of transition becomes more pronounced during product substitution if the introduction of the new product coincides with the appearance of a new technology. The additional drop of sales reflects the natural difficulties associated with a major change. But on a more macroscopic and philosophical level, there are deeper-seated reasons for the substitution dip. It constitutes a low-growth business season that gives rise to a cyclical variation. It has been otherwise observed and understood as destruction breeds growth.

As the pendulum moves, it alternates between two states: one of purely potential energy and another one of purely kinetic energy - a state of potential growth and a state of visible growth. Such periodic change has proved beneficial climatically, culturally, and socially. Such diversity is also beneficial to the business. 


\section{Natural Growth HaRmoniously Sustained}

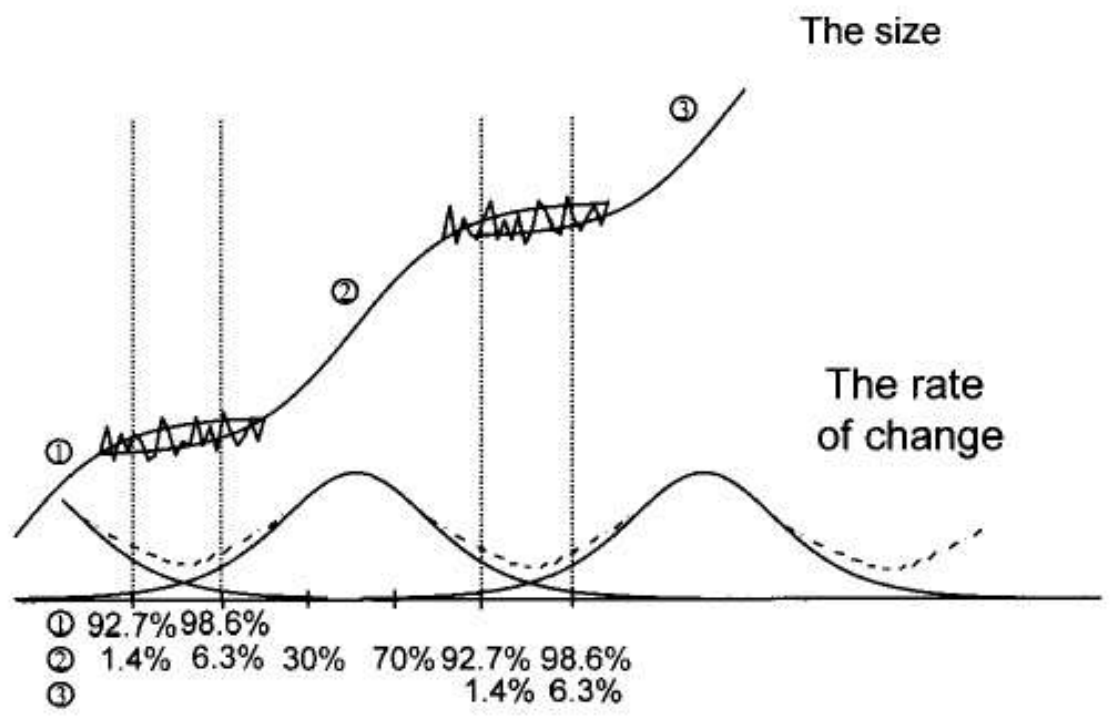

Figure 1 - Harmonic succession of natural growth processes means a pendulum swing from one market niche to the next, while survival of the fittest dictates the rule of the competition. The graph at the top shows the amount of growth achieved during the consecutive filling of three market niches. The graph at the bottom shows the rate of growth. The percentages refer to the niche penetration level. The overall rate of growth (dotted line at the bottom) indicates a cyclical sine-wave pattern. During low-growth periods chaotic oscillations become evident.

\section{The Four Season of a Growth Cycle}

Many management theorists have divided the growth cycle-typically a product's sales cycle-into segments. Theorists generally consider four periods according to the phase of growth: start-up, rapid growth, maturation, and decline. Their treatment is invariably qualitative, and the four phases are not necessarily of equal duration or precise definition.

Here the cycle phases are presented somewhat differently, using the four seasons as a metaphor. Winter reflects the critical growth period encountered during the beginning and the end of a natural growth process. Natural growth experiences two winters in its lifetime. The first winter is while the newcomer is struggling for a foothold in the competitive arena, and the second one when there is aging and the follow-up process is fighting for succession. By definition, the end of the first winter signals that the growth process has survived "infant mortality"- - that is, it has realized around 7 percent of its growth potential.

The seasons metaphor is not used for poetic justification. The advantage over more traditional segmentations is that our familiarity with the mechanisms associated with nature's four seasons can shed light on and guide us through decisions on business and social issues. For example, the low creativity observed during summer is only partially due to the heat. New undertakings are disfavored mainly because summer living is easy and there is no reason to look for change. In contrast, animals (for example, foxes and sparrows) are known to become entrepreneurial in the winter. There is wisdom encoded in nature's seasonal patterns and behaviors. These can be studied and transferred to whatever situation depicts a succession of seasonlike stages. It is conceivable to exploit this analogy all the way down to monthly behaviors.

Like the four seasons, the segments into which we divide the cycle must be of equal length. The time scale may vary widely depending on what growth process we are looking 
at. For a product, a season may last 6 months to a year. For an industry, a season may be 5 to 10 years. For the Kondratieff cycle a season may be 15 years long.

We saw in Section 1 that just-in-time product substitution is achieved when 1 percent of the new product's market penetration coincides with 90 percent saturation of the old product's market niche. This timing implies that the replacing product's first winter coincides with the incumbent product's second winter. Consequently the timing also implies that the new product must be launched during the fall season of the product it is replacing (no wonder farmers sow in autumn). Winter then becomes the time of selection, when wanton death eliminates the weak and the unfit. Spring corresponds to "adolescence", the formative years. Spring is also the time for R\&D of future replacements.

Most marketers have intuitive knowledge of this product-succession sequence. They know, for example, that the new product is promoted most heavily while the old product phases out - we can define this period more precise here as the last 12.5 per-cent of its life cycle, its second winter. They also know that research and development for the new product must parallel capacity buildup for the old product, which is approaching maximum rate of sales and profitability.

Figure 2 defines seasons not only for products but also for anything that grows in competition: markets, technologies, industries, and so on [4]. It is generally true that in spring

\section{Assigning Seasons to the Life Cycle}

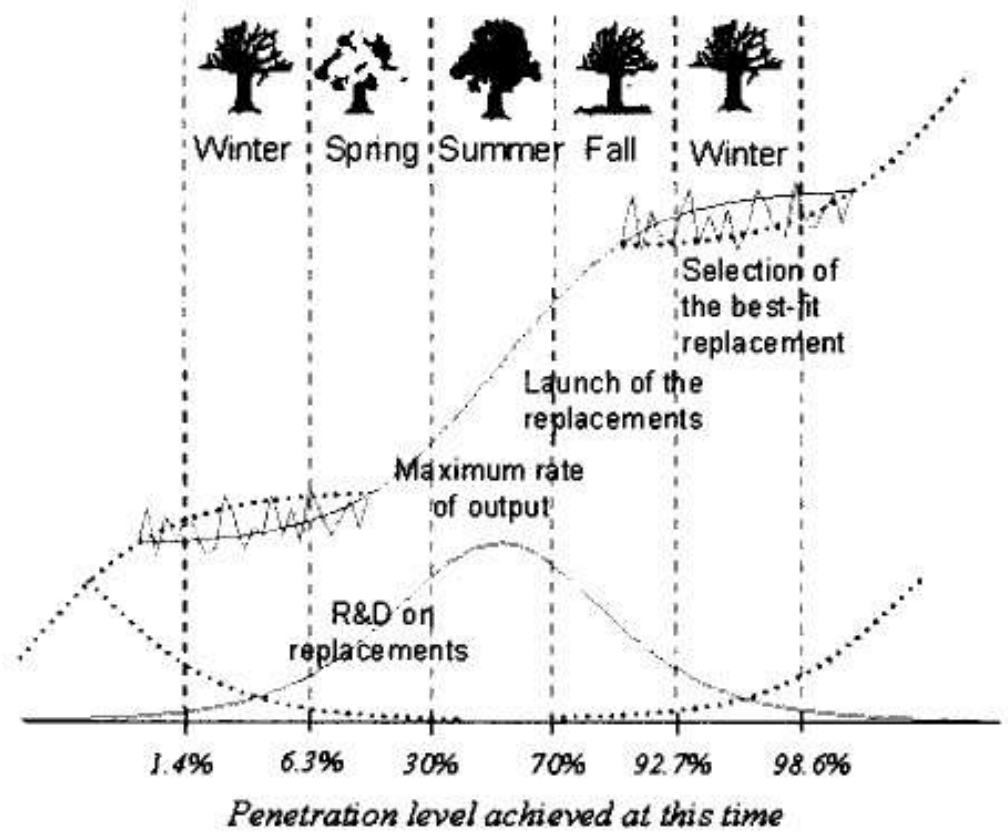

Figure 2. Segmentation of a business cycle into four seasons. The growth levels at the delimiting positions satisfy the following two conditions: (1) all seasons have the same duration, and (2) the early winter of the replacement overlaps with the late winter of the incumbent. Low-growth periods are accompanied by large and chaotic fluctuations.

one is concerned with the what and in fall with the how. That is why at the industry level product innovation occurs in spring and process innovation in fall. At the same time, at the economy level, technology and finances dominate in spring, and social and political forces dominate in fall. Spring is the time for investments. It is also the time for learning and continuous improvement. Specialists are in demand. Not so in winter. Several years ago I explained to a Geneva bank director that winter is the time to fire bureaucrats and hire Leonardo da Vincis-that is, cross-disciplinary, well-rounded men and women who stand a better chance than specialists to come up revolutionary ideas for profitable business. "Fire 
bureaucrats is exactly what we need to do, sir", he exclaimed. "Could you please tell us how to do it?" To my surprise, I heard two months later that the man had been fired.

But often what naturally happens is what should happen. As strange as it may sound, seeing specialists progressively evolve into bureaucrats may be a good sign. It is one indication that summer is setting in. The word bureaucrats carries a negative connotation, but if we call them process agents instead, we realize that they provide an important function during times of high growth and prosperity. It is during summer that enterprises become successful, centralized, conservative (no one tampers with something that works well), and in need of clockwork operations. Fine-tuning and zero defects (the original aspiration of total quality management) are particularly appropriate for a summer season. But then, what about benchmarking, continuous improvement, and BPR (business process reengineering)?

\subsection{Second Thoughts about Excellence}

Being second best hardly yields a competitive advantage. But positive feedback theories, that produce rapid fluctuations resembling chaos, argue that early gains for two simultaneously launched competitors eventually tilt the balance in favor of the "lucky" one and not necessarily the better one [5]. Early gains do not presuppose excellence.

When videocassette recorders were first introduced, the market was split between VHS and Beta. The two market shares fluctuated early on because of circumstances, luck, or marketing tactics. But soon early returns tilted the unstable situation toward VHS despite claims that Beta was technically superior. There are many such examples. Connoisseurs of personal computers value Apple products more highly than IBM computers and their clones, but the market-share gains of the latter have biased standardization in their favor.

Such manifestations of positive-feedback mechanisms have long been understood. During the nineteenth century Alfred Marshall-professor of political economy in Bristol, England-wrote that whatever firm first gets a good start will corner the market. To get a good early start, a product must appeal to the masses rather than to the elite, and that argues for postponing sophistication and refinements for a later season. New products are launched in the fall, but excellence is only excellent in the summer.

It is worth looking in more detail at each season's characteristics and how they can help us on everyday work decisions. There are advantages and disadvantages to each season. As we go through the various characteristics, keep in mind that they are meant to be in relative terms - that is, whatever happens in one season is with respect to what happened during the previous seasons. For example, to say that competition becomes lowest in spring does not mean it is negligible. It simply means that competition is relatively lower in spring than during the other seasons.

\subsection{Winter}

\begin{tabular}{|ll}
\hline $\begin{array}{l}\text { Advantage } \\
\text { New ideas }\end{array}$ & Disadvantage \\
Low profits
\end{tabular}

Winter is the beginning and the end. Death comes naturally only in winter. That is why survival becomes the name of the game. People are anxious, confused, and frustrated and explore new directions. During the chaos of the winter profound changes take place. Enterprises focus on core competencies, and organize themselves horizontally. Multidisciplinary generalists are in demand. This is the time to fire bureaucrats, train and re-skill the rest of the workforce, and mobilize entrepreneurs. The business becomes culture-driven, and enterprises go after niche markets with short-term strategies. Bottom-up cultural forces dominate and lead to segmentation, decentralization, and horizontal markets. Leadership becomes ineffective while empowerment becomes popular. 
Winter is the most difficult but also the most fertile season. Despite low morale, innovation and creativity are at a high. New directions are set. It is a period of selection. Mutations come out in great numbers and compete for the next position in power. Most of them will die, but those that make it to springtime will be ensured of a full growth cycle. Mutations serve the purpose of emergency reserves. In industry they can take the form of new product ideas, basic innovations, or other ventures. The higher their number, the better the chance that some of them will survive and grow, paving the way for the sunnier seasons that lie ahead.

The buzzwords of the management-consulting gurus that become fashionable during this season are: change management, self-management, BPR, $S B U S$ (strategic business units), and niche markets. Economically winter is the period of depression. On the product side:

- Prices become customer-driven and may not yield a profit.

- The sales force becomes opportunistic.

- Recently launched products face the acid test: will they live or will they die?

During early winter, risk-taking is encouraged, and new ways of thinking and ideas for new lines of business abound. Late winter is the time to choose among these new directions. It is critical to identify which direction will realize around 7 percent of its growth potential--the hallmark of surviving infant mortality-by the end of winter.

Industrial winters are mutational. At these times industries explore and adapt themselves in order to penetrate the maximum number of new niches. The microprocessor industry, for example, demonstrated during its winter-the first 15 years of its existence, 1970 to 1985 - an impressive ability to come up with an ever-increasing number of unexpected uses for chips. In the last 10 years, this industry has come out of winter and is climbing up the exponential growth rates of spring.

On the political scene winters often feature major wars.

\subsection{Spring}

\begin{tabular}{|ll|}
\hline Excitement & High investments \\
Advantage & Disadvantage \\
\hline
\end{tabular}

In spring, progressive growth and new opportunities bring hope, excitement, and elation. Competition reaches a relative low point as people concentrate on hard-work ethic to enhance prosperity. Spring is a period of learning and continuous improvement. It is also a period of acquisitions and investments in facilities and real estate. Operations can benefit from an attitude of wise wastefulness. Innovation in spring concerns the S-curves of one level below. For example, the spring of an industry means product innovation. The spring of the economy-on a longer time scale-means industry innovation.

On the product side, spring demands the following:

- Build capacity for and ramp up the sales of recently launched products.

- Set the prices according to the value offered.

- Do R\&D on the follow-up products.

The most solicited human resources are specialists, engineers, and designers; men and women who resemble well-hardened and sharpened tools. Leaders are trained in view of the approaching season of prosperity. In the United States today, the pollution abatement "industry" is in its spring. It has gone beyond infant mortality but has not yet reached maturity. Now at a few percent of the GNP, pollution abatement is estimated to reach a ceiling at around 10 percent. When the whole economy is in spring, inflation is low, the value of money is high, and the recommendation for stocks is buy.

Early spring is the time when chaos subsides; opportunism and entrepreneurship lose their luster. Late spring is the right time to set up leadership schools, since leaders will abound in the up-coming summer. 


\section{Advantage \\ High profits Low creativity}

As summer sets in, the enterprise becomes successful, centrally controlled, vision driven (top-down unifying forces), and conservative. You do not tamper with something that works well. You are only allowed to fine-tune it. This is the time for excellence and total quality (nine sigmas on the rate of rejects, if you can). Good leadership is in demand and enjoys stability. Process agents-inspectors who check and control processes-are also in demand. Conveniently, many specialists are now naturally evolving into bureaucrats. Strategies become long-term and strategic alliances frequent. A more vertical (stovepipe) organization comes back into fashion.

Output is at a maximum and supplies the S-curves one level below. That is, during the summer of a technology sees the largest number of successful products. The summer of the economy - on a longer time scale-sees the largest number of profitable industries. Buzzwords include vision, excellence, long-range planning, and TQM. On the product side:

- Sell, sell, sell (milk the cow).

- Dictate your prices (decadent profits).

- Integrate vertically.

To expand market share further, you do not hesitate to sell all things to all people. Advertising budgets swell. It is a period of fun and games. Firearms become popular. But comfort may lead to boredom and decadence.

Early summer is a time to stop investing and concentrate on reaping profits. But pay attention! Late summer is the turning point. Cash cows are by now getting old. It is high time to plan for the approaching days of diminishing growth.

U.S. steel companies have enjoyed the longest summer of any industry. For the better part of this century, continuous success made steelmakers conservative and immutable. But in more recent decades, the industry has been shaken by the rising popularity of competitive new materials. By the 1990s most steel industries worldwide were indulging in reorganization and process innovation, a clear sign of losing ground.

\subsection{Fall}

\begin{tabular}{|ll|}
\hline $\begin{array}{l}\text { Advantage } \\
\text { Bearing fruit }\end{array}$ & $\begin{array}{l}\text { Disadvantage } \\
\text { Aging }\end{array}$ \\
\hline
\end{tabular}

You are probably too familiar with the instinctive human reaction to loss of market share: denial, blame, and panic, in that chronological order. These are the hallmarks of the fall season. The usual rescuing efforts include tightening-the-belt programs, face-lifting efforts, and a concentration on core competencies. What is excellent to start with is benchmarking, a comparative study to find out what you are not doing quite right. A back-to-basics attitude makes operations shrink. The company disinvests from aging products and focuses on strategic accounts. On a longer time scale, the fall of an industry sees process innovation. On an even longer time scale, the fall of the economy sees recession, high inflation, and a rush toward liquidity. But deteriorating trends soon enter a state of chaos, in which erratic behavior emerges as a mechanism to explore new directions picked practically at random. Competition intensifies to a maximum resulting in high rates of homicides and criminality. Cross-disciplinary generalists must be recruited to devise revolutionary ideas for profitable new business.

On the product side:

- Set prices according to costs.

- Improve efficiency of operations, particularly on phasing-out products.

- Launch the replacement product. 
During early fall, sobering up and tightening-the-belt tactics suffice, but as the season matures, cost-cutting and face-lifting operations are no longer effective. Late fall is the time to redesign your processes and begin the search for or the training of entrepreneurs. Fall is also the time to teach what you have learned.

Figure 3 provides highlights for each season. It is possible to exploit the seasons' characteristics in order to develop investment strategies. The typical pattern is to invest in spring and goes liquid in fall.

\section{Highlights of Seasonal Behaviors}

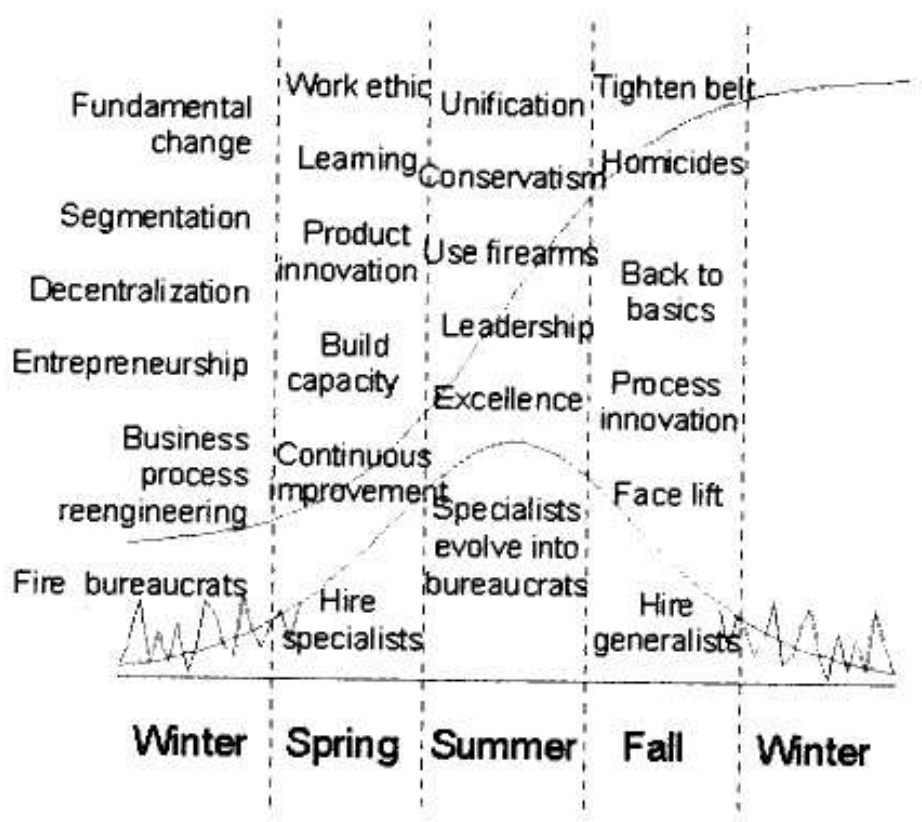

Figure 3 - Behaviors that generally fit into a given season.

\section{Riding the Kondratieff Wave}

It has been demonstrated that besides the economy, also homicides, feminism, alcoholism anti-Semitism, and other anthropomorphic behaviors of society ebb and flow with the Kondratieff wave. The following excerpt is taken from Predictions [6]: "During periods o] economic growth, criminality is low and so are bank failures. People seem to be busy working, building, increasing their prosperity. As we enter the boom years women becom the preferred target for murder. Living through the prosperous years sees people starting tc like guns, drink more alcohol, and break running records. Affluence by now does more harm than good, for life expectancy hits a low in its improvement. At the end of the boom, guns are ten times more popular than knives as murder weapons. A little afterwards, energy prices flare up like fireworks signaling the end of fun and games. Later feminism flourishes and then we enter the recession. Well into the recession bank failures soar and so do murders. Killings reach a maximum as life becomes difficult; the targets are men this time and the killers are gradually developing a taste for the knife. There is no bad without some good in it, however. By the end of the recession, life expectancy shows the highest gains, even if competitive sports have suffered. Technological discoveries and innovations abound again, while criminality decreases. The overall sobering up of the society serves as a natural preparation of the next growth phase lying ahead. And thus the cycle begins to repeat itself."

Hostile activities exhibit two climaxes. One climax concerns homicides, which rise as we approach "winter" as a result of the hard times and the competitive squeeze. The other climax concerns the use of firearms, which rises during "summer" and carries overtones of 
some kind of "entertainment". The former can be attributed to a struggle for survival during difficult times, but the latter displays the influence of affluence, gluttony, and decadence. One could appropriately characterize the two climaxes as survival-driven and greed-driven respectively.

\section{The Kondratieff Cycle as Evidenced by the Variation of Energy Consumption}

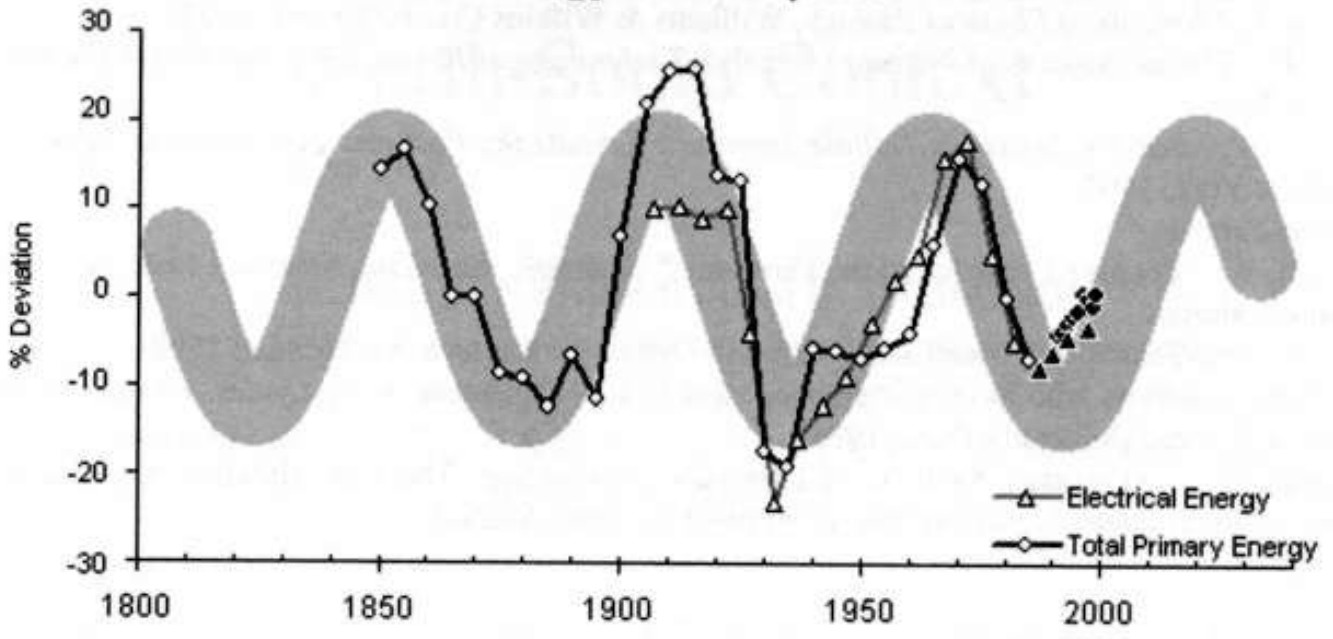

Figure 4 - The data points represent the percentage deviation of energy consumption in the US from the natural growth-trend indicated by a fitted S-curve. The gray band is an $8 \%$ interval around a sine wave with period 56 years. The black dots and black triangles show what happened after the graph was first put together in 1988.[7] Presently we are entering a "spring" season. WWI occurred in late "summer" whereas WWII in late "winter".

Wars have been shown to have a periodicity of about half that of Kondratieff's, with one outburst in times of need and another in times of affluence.[8] By analogy to criminality "winter" wars could be characterized as survival-driven and "summer" wars as greed-driven. This throws new light onto the last two world wars. It suggests that there may have been more fundamental subconscious reasons behind WWII besides Hitler's obvious imperialistic greed. Massive destruction invariably leads to growth and during the decade preceding WWII the world economy had been yearning for growth (e.g., the 1930s in the US). The implication is that WWII may have been more about survival whereas WWI and the American Viet-Nam war (one Kondratieff cycle later) may have been more about expansionism.

\section{Conclusions}

It has been amply demonstrated that society is anthropomorphic [9]. To that extent one can expect society to behave as a species while it goes through cyclical phases of growth. Wars tend to occur with a frequency double that of Kondratieff's with survival-driven wars during times of need and greed-driven wars during affluent times.

Kondratieff's cycle puts society presently in an early "spring" season. As such, we should progressively witness first chaos coming to an end, then a work ethic being installed, and then prosperity increasing worldwide. Specialists are in demand and the future directions of growth are becoming clear. Within ten to fifteen years we will have successively sampled feelings of hope, excitement, elation. The 20-year "spring" season may be foggy (in the sense of not being able to see clearly far into the future) and illusionary but it will eventually lead to economic boom and prosperity around the mid2020s. 
Present warlike activities seem to be neither of purely survival nor of purely expansionary nature but rather a mixture of the two. Next major warfare could be expected in the late 2020 s and be driven by expansionism.

\section{References}

[1] Lotka, A. J., Elements of Physical Biology, Williams \& Wilkins Co., Baltimore, 1952.

[2] Modis, T., "Fractal Aspects of Natural Growth," Technological Forecasting and Social Change, vol. 47, 1994, pp. 63-73.

[3] Modis, T., Predictions: Society's Telltale Signature Reveals the Past and Forecasts the Future, Simon \& Schuster, New York, 1992.

[4] See Note 2 above

[5] Arthur, B. W., "Positive Feedback in the Economy," Scientific American, February 1990, pp. 80-85.

[6] See Note 3 above.

[7] Modis, T., Predictions - 10 Years Later, Growth Dynamics, Geneva, Switzerland 2002.

[8] One of many authors who have written about this is J. S. Goldstein, Long Cycles. Prosperity and War in the Modern Age, Yale University Press, 1988

[9] Marchetti, C., "On Energy Systems in Historical Perspective: The Last Hundred Years and the Next Fifty," internal note, International Institute of Applied Systems Analysis. 